Buchanan, J. M. (1964). Medicine (Baltimore), 43, 697. Chanarin, I. (1964). Proc. roy. Soc. Med., 57, 384. Chanarin, 1. (1964). Proc. roy. Soc. Med. and Bennett, M. C. (1962). Brit. med. 7., 1, 27 Rothman, D., and Watson-Williams, E. J. (1963). Lancet, 1, 1068.

Donaldson, K. O., and Keresztesy, J. C. (1959). F. biol. Chem., 234, 3235

Herbert, V. (1964). Proc. roy. Soc. Med., 57, 377.
Leevy, C. M., Baker, H., TenHove, W., Frank, O., and Cherrick, G. R. (1965). Amer. Y. clin. Nutr., 16, 339

Cardi, L., Frank, O., Gellene, R., and Baker, H. (1965). Ibid., 17, 259.

Romine, M. K. (1960). F. Vitaminol., 6, 196. .

Sullivan, L. W., and Herbert, V. (1964). 7. clin. Invest., 43, 2048.

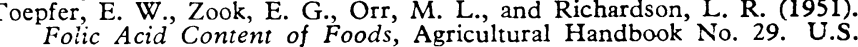
Department of Agriculture, Washington, D.C.

\title{
Value of the Vaginal Smear in the Investigation of Amenorrhoea
}

\author{
J. WILLIS,* M.D. ; J. M. G. HARLEY, $\dagger$ M.D., M.R.C.O.G.
}

Brit. med. F., 1966, 1, 399-401

The earliest suggestion that the examination of vaginal fluid may be used in the study of human ovarian function was made by Pouchet (1847). However, it was not until Papanicolaou (1933) published his classic monograph that the existence of cyclical changes in the epithelium of the human vagina and clinical hormonal cytology became established.

Since then a large volume of literature has appeared on vaginal-smear patterns before puberty, during adolescence, in pregnancy, and after the menopause. In addition, the vaginal smear has been extensively used in studying the effects of oestrogens, progesterone, and androgens on the vaginal epithelium. The literature on these subjects is too expansive for inclusion in this paper, but readers are referred to reviews by de Allende (1958), von Haam (1961), Rakoff (1961a, 1961b, 1962 ), and to symposia $(1957,1958 \mathrm{a}, 1958 \mathrm{~b}, 1959)$ in Acta Cytologica.

In contrast there is still a paucity of reports on vaginal cytology in specific gynaecological endocrinopathies, a fact commented upon by Rakoff (1961a, 1961b). In view of this it was thought desirable to analyse our material, and the results are now reported.

\section{Material and Methods}

The material under review is selective and consists of 107 patients, most of whom attended the gynaecological endocrine clinic at the Royal Victoria Hospital, Belfast. Selection was based on four criteria: (1) the amenorrhoea was either the presenting or one of the principle complaints and was of at least three months' duration; (2) the patient had not taken any hormone therapy for two months prior to or during the investigations ; (3) the cause of the amenorrhoea was established beyond reasonable doubt after complete clinical and laboratory investigations; and (4) vaginal smears were taken at weekly intervals for periods up to five weeks.

\section{Collection, Fixation, and Staining Methods}

The smears were prepared from cells obtained by lightly scraping the lateral wall of the upper third of the vagina, this being the optimal area for hormonal studies (Pundel, 1960 ; Soost, 1960 ; Wied, 1961). They were fixed immediately in a solution of equal parts $95 \%$ ethyl alcohol and ether and subsequently stained by slight modifications of either the Shorr (1941) or the Papanicolaou (1942) methods. The

\footnotetext{
* Department of Pathology, Queen's University of Belfast.

† Department of Obstetrics and Gynaecology, Queen's University of Belfast.
}

former technique is that recommended for endocrine investigations.

\section{Classification of the Epithelial Cells}

The epithelial cells in the smears were classified according to the nomenclature suggested as the result of a symposium (1958a, 1958b) on cytological terminology.

Superficial cells.-These are large polygonal cells with a completely pyknotic nucleus and either eosinophilic cytoplasm (eosinophilic karyopyknotic cells) or cyanophilic cytoplasm (cyanophilic karyopyknotic cells).

Intermediate Cells.-These are moderately large polygonal cells with a vesicular nucleus and usually cyanophilic but occasionally eosinophilic cytoplasm. In some instances where the nucleus is elongated or spindle-shaped it may appear hyperchromatic.

Parabasal Cells.-These are small round or oval cells with a large vesicular nucleus and cyanophilic cytoplasm.

\section{Classification of Cytological Curves}

The general appearances of the entire smear were first ascertained and then 500 epithelial cells over five different fields were counted in order to determine the percentages of each type of epithelial cell present, particularly the percentage of eosinophilic karyopyknotic cells. In the absence of inflammation and other factors altering the $\mathrm{pH}$ of the vagina, these latter cells were taken to represent full maturation of the vaginal epithelium and thus oestrogenic production. The percentages of eosinophilic karyopyknotic cells in each of the weekly smears were then plotted graphically and the curves obtained were representative of the degree of oestrogenic effect during the period under consideration. The different types of curves encountered are as follows:

Hypertrophic.-This curve indicates the existence of persistently high oestrogen secretion as evidenced by the high percentage (40 or more) of eosinophilic karyopyknotic cells in all or the majority of smears in each series.

Eutrophic.-This curve is evidence of normal oestrogen production and displays variation in the percentages of eosinophilic karyopyknotic cells from week to week, starting off with low levels, gradually increasing to a peak of $40 \%$ or more towards the middle of the cycle, and then decreasing again. Such criteria would, of course, be inadequate for determining whether or not ovulation had occurred, but this is not a consideration of the present study. 
Hypotrophic.-This group of curves reveals reduced oestrogenic activity and is subdivided into three types. (1) Mild to moderate: this curve also reveals fluctuations in the percentages of eosinophilic karyopyknotic cells from week to week, but they always remain below normal, rarely exceeding $30 \%$. (2) Marked: in this case the percentage of eosinophilic karyopyknotic cells shows practically no variation throughout the series and it is always low, below $10 \%$; intermediate cells dominate the picture in the smears. (3) Very marked: this curve is uniform and without oscillations throughout the cycle; the smears are usually composed exclusively of intermediate cells, but occasionally eosinophilic karyopyknotic cells may account for $1-2 \%$ of the total cell population.

Atrophic.-This curve represents the lack of oestrogen response and reveals the complete absence of eosinophilic karyopyknotic cells. Although an occasional intermediate cell is present, the smears are composed chiefly of parabasal cells.

\section{Results}

The vaginal-smear patterns associated with certain causes of amenorrhoea are shown in the Table. In view of the selective nature of the material the incidence of the various causes of amenorrhoea mentioned is not representative of that in the general population.

Vaginal-smear Patterns Associated with Amenorrhoea

\begin{tabular}{|c|c|c|c|c|c|c|c|}
\hline \multirow[b]{3}{*}{ Cause of Amenorrhoea } & \multicolumn{6}{|c|}{ Type of Cytology Curve } & \multirow{3}{*}{ 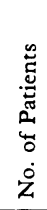 } \\
\hline & \multirow{2}{*}{ 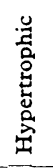 } & \multirow[b]{2}{*}{ 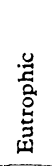 } & \multicolumn{3}{|c|}{ Hypotrophic } & \multirow[b]{2}{*}{ 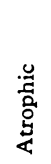 } & \\
\hline & & & 总 & 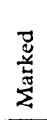 & 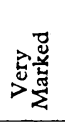 & & \\
\hline 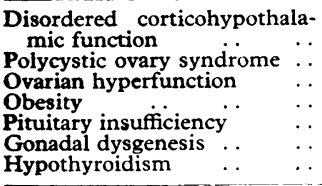 & $\frac{\overline{ }}{13}$ & $\begin{array}{l}\frac{14}{3} \\
\frac{3}{-}\end{array}$ & $\begin{array}{r}21 \\
3 \\
-5 \\
\frac{5}{5}\end{array}$ & $\begin{array}{r}2 \\
3 \\
- \\
4 \\
-\end{array}$ & $\begin{array}{r}1 \\
19 \\
3 \\
3 \\
- \\
\end{array}$ & $\begin{array}{l}3 \\
= \\
5\end{array}$ & $\begin{array}{r}38 \\
28 \\
13 \\
11 \\
7 \\
5 \\
5\end{array}$ \\
\hline . $\quad$. & 13 & 17 & 34 & 9 & 26 & 8 & 107 \\
\hline
\end{tabular}

Disordered Cortico-hypothalamic Function. - Thirty-eight patients had amenorrhoea attributable to disturbances of the cortico-hypothalamic system. The curves obtained by vaginal cytology in this group varied. However, the majority of patients had either eutrophic or mild-to-moderate hypotrophic curves. Marked to very marked hypotrophic types were infrequent. Atrophic and hypertrophic patterns were not seen in the present study. On the other hand, Rakoff (1961a, 1961b) states that, although there is great variation in smear types from atrophic to highly proliferative forms, the one most often seen in patients with psychogenic amenorrhoea is atrophic to slightly proliferative.

Polycystic Ovary Syndrome.-There were 28 patients with this syndrome. The vaginal-smear patterns in this group were not characteristic but reflected the variation that may occur in hormonal secretion. In the present study the cytology curves varied from atrophic through severe to mild-to-moderate hypotrophic types. However, the majority of patients had very marked hypotrophic forms. The three patients with atrophic smears showed more pronounced masculinization. These findings are comparable to those reported by Rakoff (1961a, 1961b). Eutrophic and hypertrophic curves were not seen.

Ovarian Hyperfunction.-There were 13 patients in this group. Hypertrophic curves were noted in all cases, indicating persistently high levels of oestrogen. The endometrium revealed varying degrees of hyperplasia, including adenomatous hyperplasia.
Obesity.-In certain individuals the response to the "stress of obesity" may cause amenorrhoea. Eleven patients in the present study had amenorrhoea attributed to this condition. The cytology patterns were inconstant, being normal in three patients, mildly to moderately hypotrophic in five, and very markedly hypotrophic in three.

Pituitary Insufficiency.-This diagnosis was made in seven cases. Four patients had marked hypotrophic smears, and in three the curve was of the very marked hypotrophic type. The follicle-stimulating-hormone values were correspondingly reduced.

Gonadal Dysgenesis.- The five patients in this group complained of primary amenorrhoea. The buccal smear was chromatin-" negative" in three of them. Atrophic type cytology curves were noted in all instances.

Hypothyroidism.-A diagnosis of hypothyroidism was made in five patients. In all cases the smear pattern was of the mild-to-moderate hypotrophic type, indicating slightly reduced oestrogen secretion.

\section{Discussion}

In the present study, with the exception of ovarian hyperfunction, the cytological curves were not specific enough to establish an aetiological diagnosis of the different causes of amenorrhoea, the various types of hypotrophic, atrophic, and eutrophic curves being noted in two or more conditions associated with pathological amenorrhoea.

However, the purpose of hormonal cytology is not so much that it should, by itself, diagnose the cause of the amenorrhoea in all instances but that it should help to assess the degree of ovarian function present. In this respect it can be very successful. Once high levels of progestogens and androgens, whether exogenous or endogenous in origin, and certain other factors previously mentioned have been excluded, the vaginal smear reflects accurately the degree of oestrogen formation within the body. Young et al. (1957) found that serial vaginal films provide a good estimate of urinary oestrogen excretion. Rakoff (1961a, 1961b) reports a similar correlation and subdivides the degree of oestrogenic effect as ascertained by vaginal smears into several categories from markedly atrophic types with corresponding urinary oestrogen values less than $6 \mathrm{~m} \mu /$ $24 \mathrm{hr}$., through moderately proliferative types with urinary oestrogen values of $44-46 \mathrm{~m} \mu / 24 \mathrm{hrs}$., to highly proliferative types with values of urinary oestrogens exceeding $132 \mathrm{~m} \mu / 24$ hrs.

By evaluating accurately the degree of oestrogenic effect the vaginal smear is of value not only in establishing the aetiological diagnosis of amenorrhoea in some cases but also in eliminating certain causes of amenorrhoea and in indicating which additional hormonal studies are necessary in other cases-for example, follicle-stimulating hormone in the urine.

In view of the fact that chemical techniques for the estimation of urinary oestrogens are elaborate and facilities for such estimations are not readily available in all laboratories but are usually confined to well-staffed and specially equipped centres, a simple procedure which gives sufficiently precise information concerning ovarian function and which could be practised in any laboratory is worthy of serious consideration.

Reports in the literature vary from the use of a single smear (Egerton, 1957) to serial daily smears (Wachtel and Plester, 1954 ; de Allende, 1958). Although a single smear may give very valuable information in some instances, it is inadequate in most cases. On the other hand, daily smears over long periods of time are difficult to obtain, being beyond the tolerance of most patients.

It is therefore imperative to reach a reasonable compromise with regard to the number of smears that are required in these cases. Vaginal smears taken at weekly intervals for periods up to five weeks, as in the present study, would appear to be quite adequate. 


\section{Summary}

Vaginal cytology has been studied in 107 selected patients complaining of amenorrhoea.

The collection of cells from the lateral wall of the upper third of the vagina and the Shorr staining technique are best for hormonal studies. Different types of cytological curves and the various cytology patterns encountered in certain conditions associated with amenorrhoea are described. A close correlation can exist between the trophic state of the vaginal epithelium and urinary oestrogen excretion.

Vaginal cytology is a very valuable test not only for ruling in and ruling out certain causes of amenorrhoea but also as a guide to further hormonal studies. Hormonal cytology should be routine in the investigation of patients with amenorrhoea, and smears taken at weekly intervals for five weeks appear to be quite adequate for the determination of oestrogen secretion.

We wish to thank Professor J. H. Biggart and Professor J. H. M. Pinkerton for their encouragement in the preparation of this work.
REFERENCES

Allende, I. L. C. de (1958). Obstet. gynec. Surv., 13, 753.

Egerton, M. E. (1957). 尹. Obstet. Gynaec. Brit. Emp., 64, 827.

Haam, E. von (1961). Acta cytol. (Philad.), 5, 320.

Papanicolaou, G. N. (1933). Amer. f. Anat., 52, (Suppl.) p. 519.

- (1942). Science, 95, 438.

Pouchet, F.-A. (1847). Théorie positive de l'ovulation spontanée et de la fécondation. Baillière, Paris.

Pundel, J. P. (1960). Acta cytol. (Philad.), 4, 221.

Rakoff, A. E. (1961a). Ibid., 5, 153.

- (1961b). Clin. Obstet. Gynec., 4, 1045.

- (1962). Acta cytol. (Philad.), 6, 532.

Shorr, E. (1941). Science, 94, 545.

Soost, H.-J. (1960). Acta Cytol. (Philad.), 4, 199.

Symposium (1957). Ibid., 1, 70.

- (1958a). Ibid., 2, 26.

(1958b). Ibid., 2, 331 .

(1959). Ibid., 3, 197.

Wachtel, E., and Plester, J. A. (1954). 7. Obstet. Gynaec. Brit. Emp., 61, 155.

Wied, G. L. (1961). Clin. Obstet. Gynec., 4, 1031.

Young, S., Bulbrook, R. D., and Greenwood, F. C. (1957). Lancet, 1, 350.

\section{Medical Memoranda}

\section{Uterine Inversion Associated with Bicornuate Uterus}

\section{Brit. med. F., 1966, 1, 401-402}

Inversion of the puerperal uterus is one of the rare complications in obstetrics. Few cases occur where the inversion is associated with congenital abnormality of the uterus. Ward and Hughes (1956) found in the literature only six cases of inversion of bicornuate uteri, and they added a personal case. An eighth case was reported by Shepler (1964).

In five of these case reports the non-gravid horn is clearly defined as being the horn which inverted; it was also the nongravid horn which probably inverted in two other cases, and in the remaining case the description is ambiguous.

The following case is therefore the first to be specifically described of inversion of the gravid horn of a bicornuate uterus.

\section{CASE RePort}

The patient was the 22-year-old Chinese wife of an Englishman. She had aborted in her one previous pregnancy. The present pregnancy was normal, and a healthy male infant, $6 \mathrm{lb} .11 \mathrm{oz}$. (3 kg.), was born by spontaneous vaginal delivery. Ergometrine maleate $0.5 \mathrm{mg}$. with hyaluronidase was given by intramuscular injection on crowning. After 35 minutes the third stage was completed by the midwife by fundal pressure and maternal effort. This was immediately followed by a persistent trickle of blood in spite of a repeat injection of ergometrine. The patient became shocked with a blood-pressure of $80 / 60 \mathrm{~mm}$. Hg. Difficulty in finding the uterus abdominally was attributed at the time to atonicity of the uterus, and it was noted that the uterus did not respond to "rubbing up."

Resuscitation included intravenous dextran and tilting of the bed head-end downwards. The patient's condition improved within the half-hour and the uterus appeared to be normally contracted. Altogether about $40 \mathrm{oz}$. (1.1 litres) of blood had been lost ; this was replaced by blood transfusion. Subsequent progress was uneventful, and she was discharged on the tenth day.
On the following day she presented herself to the generalpractitioner clinic complaining of a "lump down below." In the vagina a large mass was present which, as the doctor described it, "looks like placenta." It was not tender and was not bleeding. An attempt was made to remove it with sponge forceps, but this proved impossible.

On readmission to hospital that day the mass was just visible at the introitus; it filled up the vagina and appeared to be continuous with the cervix. The surface was raw and bled readily on touch. The uterus could not be felt on abdominal palpation. A provisional diagnosis was made of inverted uterus.

At examination under anaesthesia later the same day inversion of the uterus was confirmed. An unsuccessful attempt was made to replace the uterus manually. Immediately after this the hydrostatic method of O'Sullivan (1945) was used, but this also failed.

On abdominal exploration three days later the uterus was found to be bicornuate-bicornis unicollis. The left non-gravid horn was visible and appeared to be normal in size and shape. The left Fallopian tube and ovary were also normal. On the right side the other horn was not visible, but instead there was a thick rim with a hole in the middle of it, out of which the right tube and round ligament appeared (Fig. 1).

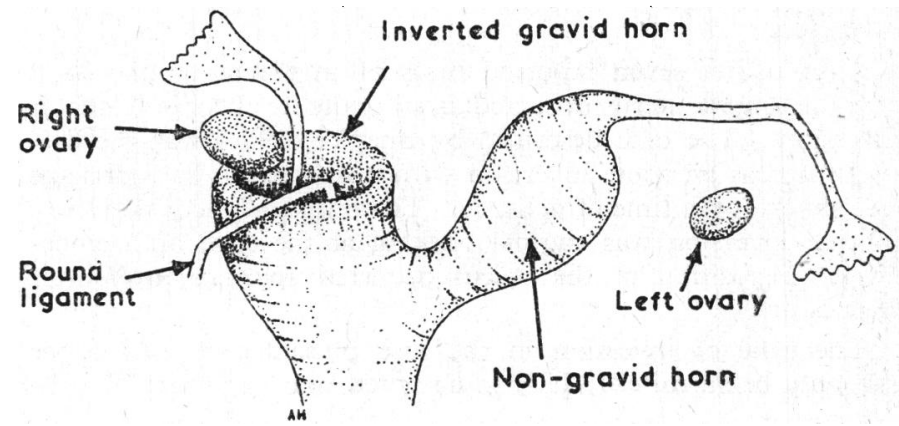

Fig. 1.-Diagram of inversion of gravid horn of bicornuate uterus as seen at laparotomy.

The ring was incised vertically on its posterior aspect, and an opening made into the vagina. Through this opening a finger was passed and the uterus invaginated (Fig. 2). The incision along the posterior wall of the uterus was sutured in two layers with interrupted catgut sutures. Bleeding was minimal. After this the round 